\title{
LA RESPONSABILIDAD INTERNACIONAL DE LA ORGANIZACIÓN MUNDIAL DE LA SALUD (OMS) EN TIEMPOS DE PANDEMIA
}

\section{THE INTERNATIONAL RESPONSIBILITY OF THE WORLD HEALTH ORGANIZATION (WHO) IN TIMES OF PANDEMIC}

Millitza Franciskovic Ingunza* Jorge Luis Godenzi Alegre**

* Doctora en Derecho, docente universitaria, conferencista.

* Abogado y asesor legal en tema de Derecho Patrimonial.

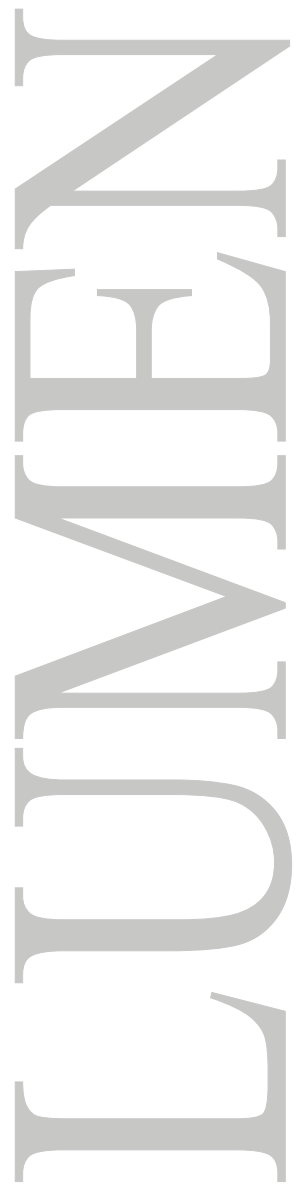




\title{
LA RESPONSABILIDAD INTERNACIONAL DE LA ORGANIZACIÓN MUNDIAL DE LA SALUD (OMS) EN TIEMPOS DE PANDEMIA
}

\section{THE INTERNATIONAL RESPONSIBILITY OF THE WORLD HEALTH ORGANIZATION (WHO) IN TIMES OF PANDEMIC}

\author{
Millitza Franciskovic Ingunza \\ Jorge Luis Godenzi Alegre
}

\section{RESUMEN}

La Organización Mundial de la Salud tiene la elevada responsabilidad de gestionar eficazmente el virus que ha provocado la pandemia que viene asolando actualmente al planeta. Es un organismo cuya función cardinal es proteger la salud de la humanidad entera.

Sin embargo, se puede advertir que el comportamiento de la OMS ante esta tragedia ha sido el de haber actuado con una tremenda lentitud. Ha escaseado de los reflejos necesarios a fin de reanudar con las funciones que le fueron encomendadas en su documento constitutivo.

En el presente artículo consideramos la existencia de responsabilidad internacional por parte de la OMS en la figura de quien actúa como Director General. Cualquier organización internacional debe dar cuenta de su conducta en circunstancias tan graves.

\section{PALABRAS CLAVE}

Organizaciones internacionales - Responsabilidad internacional - Organización Mundial de la Salud - Derecho Internacional Público.

\section{ABSTRACT}

The World Health Organization has a high responsibility to effectively manage the virus that has caused the pandemic that is currently ravaging the planet. It is an organism whose cardinal function is to protect the health of the entire humanity.

However, it can be seen that the behavior of the WHO in the face of this tragedy has been that of acting with tremendous slowness. It has lacked the necessary reflexes in order to resume the functions that were entrusted to it in its constitutive document.

In this article, we consider the existence of international responsibility on the part of the WHO as the DirectorGeneral. Any international organization must account for its conduct in such dire circumstances.

\section{KEY WORDS}

International organizations - International responsibility - World Health Organization - Public International Law.

\section{INTRODUCCIÓN}

La pandemia del coronavirus indudablemente ha producido una conmoción en las relaciones internacionales y desde ese prisma, en un aspecto cardinal el derecho internacional se constituye en una magnífica apoyatura para proponer en este artículo lo que consideramos toda una cadena 
de responsabilidades de índole legal a partir de las cuales se extraen lecciones y perspectivas que modestamente consideramos innovadoras.

Por este motivo resulta entonces legítimo enunciar la pregunta respecto de la responsabilidad legal internacional de la Organización Mundial de la Salud (OMS) como organismo especializado de las Naciones Unidas, puesto que en sus primeras manifestaciones se evidenció una clamorosa minimización del riesgo, habiendo administrado un inexplicable silencio que denotó haber faltado a su debida diligencia y no reaccionar debida y apropiadamente ya que los meses que se perdieron fueron determinantes para llegar a la tan angustiante situación en la que actualmente el mundo se debate. Para enfilar nuestro enfoque hemos creído conveniente delimitar convenientemente el ámbito de la competencia que le asiste a la Organización mundial de la Salud (OMS) para de esa forma entender porque ha sido objeto de múltiples y justificados cuestionamientos, fundamentalmente en la persona que ocupa actualmente el cargo de Director General.

Lo del coronavirus (COVID 19) no es sólo una pandemia. Es una aterradora advertencia ante la ineluctable crisis ambiental que sufre el planeta, lo cual ha conllevado a numerosos y exhaustivos estudios de los más prestigiosos profesionales de las diversas disciplinas de las ciencias sociales y las ciencias naturales, así como la de la apabullante e inconexa información que brota de los medios de comunicación, redes sociales y de los analistas, quienes con sus respectivos sesgos ideológicos, nos plantean un sinnúmero de razones que no se aproximan a responder a nuestra inquietante pregunta; en ese sentido, el primer objetivo que nos hemos trazado es indagar y reflexionar respecto a la consecuencias de derecho que traería aparejada la incuria alarmante expuesta de la Organización Mundial de la Salud al no haber informado oportunamente sobre el covid 19.

\section{NATURALEZA JURÍDICA DE LA ORGANIZACIÓN INTERNACIONAL. -}

Todas las Organizaciones Internacionales catalogadas como sujetos del Derecho Internacional Público, son asociaciones de Estados que tienen diferentes fines. Poseen personalidad jurídica internacional, es decir tienen la suficiente capacidad para instituir normas internacionales, celebrar tratados y ser a su vez destinatarios de dichas normas. Asimismo, estas organizaciones son de carácter mundial y regional. Las Organizaciones de alcance mundial son aquellas asociaciones de Estados o de otros sujetos del derecho internacional, que adquieren distintos fines y que abarcan a casi la totalidad de Estados y tienen la categoría jurídica de organizaciones especializadas de las Naciones Unidas.

La OMS es una organización especializada de la Naciones Unidades, cuyos fines están palmariamente establecidos en el documento que la constituye y que será examinado posteriormente.

\section{FACULTADES DE LA ORGANIZACIÓN INTERNACIONAL}

Las facultades de las organizaciones internacionales en la que se regulan su funcionamiento, como categoría de sujetos del derecho internacional, están debidamente afincadas y establecidas en su instrumento constitutivo.

Los aspectos relacionados al ejercicio pleno de sus facultades yen consecuencia a los derechos que la subyacen está comprendido en su estructura organizativa, la misma que puntualmente encuadra dichas facultades. Sin conocer esas prerrogativas, no se podría detectar la verdadera magnitud del ejercicio de sus derechos y la aptitud para contraer obligaciones de carácter internacional. 
Por esta razón las organizaciones internacionales están integradas por Estados; su accionar tiene como fundamento los poderes otorgados por éstos (Estados miembros) a las organizaciones internacionales, conforme a lo expresamente señalado en su instrumento constitutivo. La doctrina sostiene que los poderes, derechos y obligaciones de las organizaciones internacionales derivan de lo establecido en sus documentos que las instauran.

El fundamento de estas facultades o poderes radica en que sólo los Estados ostentan soberanía, ser soberanos es lo que constituye la fuente de poder en el sistema internacional. Vale decir sólo los Estados miembros de una organización que han sido constituida por su voluntad y en aplicación y uso de su soberanía, son los que libre y soberanamente delegan facultades, poderes, derechos y obligaciones a la organización, lo que nos lleva a inferir que, sin esta delegación de poderes o facultades, la organización internacional, no puede ejercer por sí mismo ninguna facultad.

Salvadas la naturaleza de la génesis de esas facultades, comprenderemos que este concepto es sumamente relevante para entender que, si los Estados miembros le facultan libremente a la organización respecto de algún accionar en virtud de la soberanía, elemento intrínseco al Estado, tiene razón y justificación su existencia. Una organización sin este elemento de delegación de facultades por parte de un Estado miembro no tendría razón de existir.

Claro es que una organización internacional solo tiene existencia porque su constitución está conformada por Estados, esto es, no tiene nacimiento y en consecuencia existe merced a la aquiescencia de los otros Estados.

Y a fe que así ocurrió cuando se formuló una consulta a la Corte Internacional de Justicia para enterarnos si se podía considerar a una organización como sujeto del derecho internacional, la consulta fue absuelta en los términos de que si bien una organización internacional no puede equiparársele a un Estado, y tampoco considerarlas como si fuese un súper Estado, sin embargo, al poseer derechos y obligaciones, plasmados en sus documentos constitutivos, permite reconocerlas como sujetos del derecho internacional.

Empero, a pesar de que ellas puedan parecer en extremo poderosas, su real fuente de poder radica en el poder soberano de los Estados. En consecuencia, su capacidad de acción está estrictamente limitada y está determinada en el respectivo instrumento constitutivo.

A este respecto y tal como sostiene (Urueña, 2008) en el caso de las Comunidades Europeas y de la Unión Europea: a pesar de su gran poder político, y a pesar de que pueden ser clasificadas como organizaciones supranacionales, sus poderes dependen estrictamente de la delegación que los Estados miembro realicen. En este sentido, es una organización internacional como cualquier otra, aunque, ciertamente, la más integrada jamás vista en la historia. Y aunque en la época contemporánea pueda conducirnos a pensar del gran poder e influencia política de las organizaciones internacionales, lo real es que no tienen la categoría de sujeto pleno, como el Estado soberano por excelencia, auténtico protagonista del derecho internacional y de las relaciones internacionales puesto que responden al poder soberano de la nación a la que representan.

Por eso las organizaciones internacionales están regentadas por el principio propio del derecho internacional, denominado "Lotus", que fue formulado inicialmente por la Corte Permanente de Justicia Internacional en la decisión del mismo nombre, en virtud del cual el derecho internacional es un sistema permisivo en lo que se refiere a la conducta de los Estados, ello significa que estos pueden hacer todo lo que anhelen, siempre y cuando no les esté prohibido de manera taxativa. 
Además, el principio 'Lotus' se ve complementado por el denominado 'principio Wimbledon'. En 1923, la Corte Permanente de Justicia Internacional se enfrentó a una paradoja clásica del derecho internacional: ¿puede un Estado limitar el ejercicio de su soberanía mediante la celebración de un tratado? Según dispuso la Corte en el caso del S. S. Wimbledon (y la doctrina prácticamente uniforme desde entonces), los Estados no limitan su soberanía mediante la celebración de un tratado. Por el contrario, celebran tratados, precisamente porque son soberanos. Esta respuesta, al decir de Urueña plantea la idea de que la limitación de la soberanía como ejercicio de ella es un instrumento útil para salvar la estabilidad del sistema jurídico internacional, pero no nos suministra un criterio jurídico sustancial para decidir si tal limitación sería conforme a derecho.

Visto en esencia, nos dice que tal limitación será legal si el Estado soberano decide imponérsela, sin que importen las razones que motiven tal decisión. En todo caso, el principio de permisividad dispuesto para los Estados se invierte en lo que concierne a las organizaciones internacionales, en el sentido de que éstas, pueden hacer solamente aquello que les está permitido, vale decir, las organizaciones internacionales, no tienen autonomía en sí mismas.

A tenor de lo expuesto, las facultades, poderes, derechos de una organización internacional estará condicionada, limitada por la concesión de los mismos por parte de los Estados miembros. Ese es el criterio y razonamiento de derecho y por supuesto de fondo, y, por lo menos en principio, no parece haber manera de evitarlo "[...] mientras que los Estados sean libres de actuar desde que lo hagan de acuerdo con el derecho internacional (que puede prescribir o proscribir actividades del Estado), las organizaciones internacionales tienen capacidad de actuar solamente en la medida en que hayan sido atribuidos a ellas ciertos poderes por los Estados miembro".

Es más, los poderes de las organizaciones internacionales resultan relevantes, pues definen los actos que pueden emprender, esta categoría de sujetos de manera legal, así como los actos que son excluidos de su ámbito de competencia. Los actos emprendidos fuera del área de competencia de la organización internacional se denominan actos ultra vires; por el contrario, aquellos que recaen en el ámbito de facultades de la respectiva organización se denominan actos intra vires. Los primeros, es decir los actos ultra vires, aunque parezca paradójico son muchas veces antagónicos a la normativa y al propio derecho de las organizaciones internacionales. Los actos realizados fuera del ámbito de la competencia de la organización, sería un acto que vaya en contra de la voluntad de los Estados miembros y de su respectivo documento constitutivo. Así entonces podría constituir un ilícito internacional del cual derivaría en responsabilidad de parte de la organización respectiva.

Es innegable que, por tal motivo, es de fundamental importancia definir cuáles son las facultades y poderes de una organización internacional para fijar si su accionar se ciñe dentro de su competencia.

Lo cierto es que existen, en esencia, tres doctrinas que definen tal cuestión: una organización internacional puede emprender cierta tarea solamente si sus Estados miembros le han delegado las facultades para llevarla a cabo, ya sea, 1) de manera explícita o en su defecto 2) de forma implícita. Además, es posible afirmar que una organización internacional tiene el poder 'inherente' de hacer algo que responda a su naturaleza funcional.

En este sentido, es de suyo muy relevante entender que el accionar de una organización internacional está sometida a la delegación de poderes que le concede los Estados miembros que la constituyen y que obra expresamente en el tratado que crea dicha entidad. 
Entretanto quiere decir que la tendencia que se viene empleando está orientada hacia la idea de que las facultades de las organizaciones deben estar explícitamente reseñadas en sus documentos constitutivos.

\section{RESPONSABILIDAD DE LAS ORGANIZACIONES INTERNACIONALES}

No por casualidad y tal como lo apuntalaremos en líneas precedentes existen dos categorías de actos que realiza una organización internacional: Los actos emprendidos fuera del área de competencia de la organización internacional, que se denominan actos ultra vires; y por el contrario, aquellos que recaen en el ámbito de facultades de la respectiva organización se denominan actos intra vires.

Es significativo encomiar y reconocer que el estudio de la responsabilidad de las organizaciones internacionales es de reciente data. Hay un sector de la doctrina internacional que estima que se debe estudiar y encaminar la problemática de la responsabilidad de las organizaciones internacionales, desde la categoría de aquellos actos emprendidos fuera del área del ámbito de la competencia de la organización internacional, que tal como lo hemos manifestado se denominan actos ultra vires.

Sin embargo, de acuerdo a los informes técnicos elaborados por reputados estudiosos de este asunto, se puede partir del entendido de lo que manifestara el profesor René Urueña en su texto: Derecho de las organizaciones internacionales de que:

Sólo los Estados miembros, en el uso y ejercicio de su soberanía, pueden delegar solo ciertos poderes a la organización. Sin esta delegación, la organización, por sí misma, no tendría ningún poder y solo pueden hacer aquello que les está permitido (Urueña, 2008 p.209).

No en vano puede afirmarse que en la vida internacional el comportamiento de las organizaciones internacionales está sometido a "reglas", es decir, al conjunto de competencias, poderes, funciones y normas de funcionamiento.

En función de ello, para determinar la responsabilidad de las organizaciones internacionales se debe de encuadrar su estudio desde la categoría de los actos denominados ultra vires, esto es, los actos que emprende la organización internacional fuera del ámbito de su competencia.

\section{RESPONSABILIDAD DE LAS ORGANIZACIONES INTERNACIONALES POR ACTOS ULTRA VIRES}

Transita por la Corte Internacional de Justicia quien ha desarrollado, analizado y examinado estos tópicos en lo que atañe a la suficiencia jurídica de las organizaciones internacionales, alineadas siempre con lo que se encuentra prescrito en la tan celebérrima Convención de Viena de 1986 que contiene el derecho de los Tratados entre todos los Estados reconocidos y de las Organizaciones Internacionales. No obstante, conforme lo sostiene Huici, el complejo equilibrio entre la práctica y las disposiciones del Tratado constitutivo y otros actos vinculantes, adoptados por sus miembros o por la propia organización internacional esboza con trazo sinuoso el contorno de la autonomía de la organización internacional como sujeto "diferenciado" de sus Estados miembros. (Huici, 2007). 


\section{RESPONSABILIDAD INTERNACIONAL Y DOCTRINA ULTRA VIRES}

Viendo el recital de razones que se han manifestado al principio, el tema de la responsabilidad internacional de las organizaciones internacionales es un tema relativamente inédito, tanto en su discusión epistemológica como en su desarrollo jurídico.

Pero el derecho internacional nos plantea el problema a través de propuestas tendientes a señalizar las responsabilidades de las Organizaciones Internacionales respecto de comportamientos institucionales de fuerte connotación anti jurídicas. Nos parece que las contribuciones más significativas están delineadas al esfuerzo por definir los conceptos vinculados con el andamiaje y el desarrollo de las Organizaciones Internacionales, puesto que se conoce que la personería jurídica de las organizaciones internacionales tiene el carácter de objetiva, vale decir que no se encuentra sometida por parte de un Estado que resulte dañado por su irregular conducta y que podría ser declarado responsable internacionalmente por actos de implicancia ilícitas porque su manifestación de voluntad es absolutamente autonómica a la de los miembros que la integran y que en su desenvolvimiento no se conducen a través de su plana funcionarial sino también lo hacen por medio de otras colectividades de carácter internacional.

Con solo contemplar y analizar la opinión técnica consultiva sobre la aplicabilidad del Artículo VI, Sección 22 de la Convención sobre Privilegios e Inmunidades de Organización de Naciones Unidas, la Corte Internacional de Justicia puso en conocimiento que el desenvolvimiento funcional de la Organización de Naciones Unidas incorpora y compromete no solo a sus órganos principales y subsidiarios, sino que también están igualmente inmersos los funcionarios y/o agentes que las representan. Se colige entonces que cualquier oficina o sector que se desprenda de la Organización Internacional podrían delegar funciones y responsabilidades a algunos funcionarios e inclusive a algunas dependencias internacionales.

En definitiva, a fin de delimitar la prerrogativa funcional de naturaleza subjetiva de la responsabilidad estará sujeta a estandarizar si el ilícito internacional es imputable a la Organización Internacional como tal o de pronto achacárselo a uno de sus órganos dependientes, a uno o varios Estados miembros o acaso a un funcionario explícito de la organización. Por doctrina y costumbre se comprende que en las dos primeras situaciones será, qué duda cabe, la propia Organización Internacional la que se responsabilice a responder y a despejar las dudas que se ciernen en su comportamiento institucional y si eventualmente la responsabilidad recae por actos, conductas $u$ omisiones de los propios Estados entonces los requerimientos se podrán formular indirectamente contra ese o esos Estados gravemente involucrados en el ilícito internacional.

Es menester asentar algunas ideas que son propias e inherentes a la doctrina del derecho internacional. Numerosos profesores han coincidido y es natural que fuere así por seguir una línea lógica sostenida en el tiempo que, en cuanto a la responsabilidad de las personas jurídicas, llámese Organizaciones Internacionales, habrá que deslindar primero si sus funcionarios, por acción u omisión al cometer el ilícito internacional se hallaban en servicio porque incluso si el acto fuera ultra vires, infortunadamente la Organización Internacional estaría emplazada a responder. Pues, si el Estado miembro abandona su función de establecer políticas de control efectiva respecto de la andadura de su propia organización puede y nos parece que debería de asumir la responsabilidad al haber demostrado palmariamente una conducta institucional sumamente desidiosa y negligente. Infortunadamente estas localizaciones no se encuentran claramente descritas y mucho menos definidas en lo que incumbe precisamente a los procedimientos de registro y control de las acciones que llevan a cabo los funcionarios o agentes de las organizaciones internacionales. Podría ser en 
todo caso que la responsabilidad finalmente recaiga compartidamente entre la Organización o el funcionario que la personifica.

En todo caso, la facultad de naturaleza subjetiva de la tan opinable responsabilidad internacional puede otorgarse a los funcionarios, dependencias internacionales o los Estados afiliados de la Organización, sin embargo, hay otras estimaciones que consideran que el criterio a emplear sería el control específico sobre el acto concreto. Si uno de los agentes severamente involucrados ejerce registro y comprobación sobre la conducta funcional del agente que incurrió en el ilícito internacional, el primero de ellos será estrictamente responsable, según el sistema jurídico que le resulte aplicable y no precisamente al respectivo agente. (Klabbers, 2001).

Evocando el artículo 2 del Proyecto sobre responsabilidad internacional de las organizaciones internacionales señala: El comportamiento de un órgano o un agente de la organización internacional se considerará hecho de esa organización según el derecho internacional si tal órgano o agente actúa en esa condición, aunque ese comportamiento exceda de la competencia del órgano o agente o contravenga sus instrucciones.

En torno a este examen diáfanamente el artículo incorpora las acciones ultra vires y atribuye responsabilidad a la organización sea por acciones de los órganos o de sus agentes. Si bien el Proyecto aún no tiene fuerza vinculante, la Corte Internacional de Justicia ha puesto de manifiesto su posición en el sentido de que la problemática del ultra vires no imputable a la Organización Internacional, sino a las personas que no tuvieran nexo no le ocasiona obligación legal alguna, pero si se hacen responsable de los actos funcionales de los agentes de su servicio o del propio órgano internacional.

Aunque sea fácil establecer la responsabilidad indirecta o subsidiaria, todo eso depende de la relación que tengan las organizaciones internacionales con todos y cada uno de sus componentes. Respecto a este asunto se podrían exteriorizar dos posiciones claramente diferenciadas: la primera resguarda celosamente la personalidad jurídica de la organización internacional y en consecuencia su total independencia y autonomía por lo que achacarle responsabilidad por conductas funcionales de la organización a sus integrantes vendría a ser casi lo mismo que asignarle responsabilidad a un Estado por hechos cometidos por otros. La otra posición estriba cuando los Estados perciben que las organizaciones internacionales trasladan solo la expresión diáfana de voluntad o de los intereses que representan, lo cual quería decir que los Estados también tienen cierta competencia para ejercer dirección y control respecto de las actividades que despliega la Organización Internacional, ya que apartar a los Estados miembros de responsabilidad respecto a las organizaciones internacionales sería absolutamente artificioso.

Dando la impresión de abundar en todo lo expuesto, habría que glosar lo manifestado por la Corte Internacional de Justicia en el que sostiene: "Que desde el punto de vista de la ontología del poder, la Corte define que todos los agentes, funcionarios o servidores particulares de la Organización de Naciones Unidas, cualquiera que sea el cargo oficial que desempeñen, han de desempeñarse con las limitaciones que le impone el cargo de forma que no se propasen en su actividades funcionales, pues han de desenvolverse rectamente a fin de impedir o evitar explicables reclamaciones contra la Organización de las Naciones Unidas.

A este fin, la responsabilidad indirecta se entiende a que solo sus componentes asumen plena responsabilidad ante la propia organización, así como en el caso de que se le deleguen prerrogativas para asumir obligaciones frente a legítimos terceros, es el caso citar cuando se trata de cancelar 
las cuotas extraordinarias. En estas situaciones la disyuntiva se encuentra en saber si se mantiene una postura a través de la cual la organización internacional es plenamente autónoma respecto de sus componentes a fin de reparar, por lo que nos encontraríamos ante la responsabilidad indirecta o denominada subsidiaria, pues carecería de sentido. Es oportuno añadir que el reconocimiento previo de la personalidad jurídica trae de suyo la invariable intención de las partes a constituir una colectividad separada de los Estados que la integran.

En la realidad pragmática se produciría una cuestión sumamente opinable y es que, en esta problemática ante las organizaciones internacionales, éstas no se encuentran perfectamente legitimadas, ni por ruta activa ni por ruta pasiva, para participar procesalmente ante los tribunales internacionales e inclusive alegar inmunidades. Es cierto, como apuntan algunos comentaristas, que coexiste una insuficiencia de cláusulas expresas por parte de las Organizaciones Internacionales en sus instrumentos constitutivos, y en los casos sumamente extraordinarios se encontrarían presentes y actuantes solamente instituciones de carácter económicas o en organizaciones cuyo desarrollo de actividades implique riesgos financieros.

Estando claras estas posiciones, recapitulemos que, por tener y ejercer plenamente la soberanía, la autoridad de los Estados no está sujeta en ningún aspecto a otra entidad internacional, en tanto las organizaciones internacionales se subordina a los poderes que le fueren designados para realizar y cumplir con sus funciones que les han sido asignadas por los Estados miembros.

Como no parece de otra manera, cabría formular la pregunta sobre la legalidad de los actos de las organizaciones internacionales llevados a cabo excediendo, en algunas ocasiones, sus poderes y competencias o que de pronto no se encontraba encuadrado con el instrumento constitutivo, es decir, actos ultra vires. Un acto ultra vires es aquel realizado sin autoridad para actuar en la materia, sin embargo, no existe una definición de actos ultra vires.

En aquellas situaciones, ¿Quién o quiénes podría incoar reclamación o petición alguna respecto a aquellos actos, hechos o conductas que conlleven excesos en los poderes o facultades de las Organizaciones Internacionales? ¿Acaso los mismos Estados miembros? ¿Podría ser los terceros afectados?

Fijándonos en esta situación, la doctrina del derecho internacional mantiene posiciones discordantes. De una parte, se sostiene y se apoya la tesitura de que los actos, hechos o decisiones que patrocinan las organizaciones internacionales cuando se extralimitan en sus funciones o poderes devienen en inválidos y que los Estados miembros afectados directa o indirectamente pueden declinar o desdeñar a poner en funcionamiento las decisiones que consideren irregulares por ser abiertamente inconstitucionales. La otra tesitura consiste en defender a rajatabla la controvertida doctrina ultra vires por el cual no se aplica a las organizaciones internacionales puesto que sus actos y decisiones son ulteriormente siempre legales y válidos. Indiscutiblemente la más óptima y la mejor consentida es aquella que sostiene y mantiene que las organizaciones internacionales tienen la suficiente capacidad de consumar actos ultra vires y que los poderes de los que le son abastecidos no son incontrolados, sino que, todo lo contrario, se sujetan a su propia normatividad en razón de que su aptitud para ejercer sus derechos y asumir obligaciones deben encontrarse debidamente explicitadas en sus instrumentos constitutivos. Como acertadamente los señala el profesor René Urueña "los actos ultra vires son contrarios al derecho de las organizaciones internacionales", porque, como es lógico, transgrede el documento constitutivo base a través del cual se cristaliza diáfanamente la libre voluntad de los Estados. La burla o contravención de las reglas prescritas de la institución se constituye en un factor que posibilita el elemento objetivo por el cual una organización 
internacional puede recaer en responsabilidad porque se trata de una flagrante violación de su propia normatividad que le brinda consistencia y vigencia a la institución.

Otros acuciosos doctrinarios estiman que existen ciertas facultades o prerrogativas que concede los actos ultra vires que sería oportuno y conveniente precisarlos. Porque al abordar de actos per se está aludiendo a las decisiones o posturas lanzadas por los respectivos órganos de las organizaciones internacionales; una segunda razón estriba en que las prerrogativas o poderes pueden ser estrictamente constitucionales o que se desprendan de legislación accesoria o secundaria.

Vaya por delante lo que en términos generales se pone de manifiesto cuando se desestima aplicar o ejecutar una determinada resolución bajo el influjo doctrinal del ultra vires, pero lo que lamentablemente se soslaya son los mecanismos o procedimientos de cuestionamiento para esos actos, como es el caso citar, el de una acción de nulidad. Lo que en teoría y principio debiera ser una manifestación de hondo contenido jurídico concluye siendo un posicionamiento netamente político por parte de los Estados o accidentalmente ser explícitamente concedidas merced a ciertas actividades interpretativas; o, en su defecto, en un uso abusivo y desviado de poder que puede concluir como resultado de la omisión de provisiones fundamentales como de procedimientos regulares; en cuarto renglón tenemos lo que se registra y evalúa es la validez o eficacia de los actos y el desarrollo de los poderes, atención, no la legalidad, en los términos de trasgresión de las obligaciones, como el de reparar oportunamente; y el quinto renglón gravita en cuestiones puntuales sobre el despliegue de poder que puede afectar los derechos y obligaciones de otros mucho más relevante que el propio organismo.

Y es admisible que en un dictamen consultivo respecto de algunos gastos que realizó la Organización de Naciones Unidas la Corte Internacional de Justicia resolvió que si se acoge que la acción sobre la que versa se encuentra sumido en el ámbito de las funciones propias de la Organización, pero se aduce que ha sido incoada de una manera que no se ajusta a la división de funciones y atribuciones entre los indistintos órganos constituidas en la Carta constitutiva, se genera un serio alejamiento hacia el lado interno, o en su defecto directamente a la estructura más profunda de la Organización. Ahora bien, si la acción de pronto fue concluyente a través de un órgano que precisamente no era el más competente, se trataría entonces de una grave anormalidad desde el prisma de esa estructura profunda a la que nos hemos referido. Pero si en cambio dicha acción certifica y avala la obtención de los fines y objetivos de la organización se presume con justificada razón que dicha acción no puede ser considerada ultra vires.

Por lo demás, de la línea de pensamiento que acabamos de exponer podríamos colegir que los actos ultra vires pueden ser corregidas en tanto y en cuanto la Organización Internacional haya cumplido cabalmente con el fin para el cual fue concebida. Sin embargo, si existiera la alta probabilidad de mejorar o rectificar esas acciones, pues eso no eliminaría de manera automática la responsabilidad que incurra la organización internacional por el rotundo impacto que las acciones ultra vires puedan acaecer en los particulares, en el propio sistema de la organización o ante los propios Estados miembros y otras clases de organizaciones internacionales. Ahora bien, si se estropea derechos e intereses de los particulares, en esa eventualidad, debería ser competente un Tribunal nacional o en su defecto uno internacional, reconociendo el contexto en el que se desarrolló la acción. Desde el plano interno, cuando se perjudica el sistema normativo de la organización internacional y en esta circunstancia se podría aplicar las normas del derecho internacional o las propias normas de la institución o en todo caso aplicar inclusive los principios generales del derecho o el derecho administrativo internacional. 
Asimismo, las acciones de las organizaciones internacionales pueden tener efecto sobre los Estados u organismos internacionales; en esta contingencia habrá que tomar en cuenta si el ejercicio pleno de poder fue ultra vires en estricta razón de la constitución o de la legislación accesoria y su evaluación determinante se ejecutaría a escala internacional, aplicando por supuesto el derecho internacional.

Salvadas las distancias y de acuerdo a la invaluable opinión ilustrada para los efectos de las resoluciones del Tribunal Administrativo de la Organización de Naciones Unidas la Corte Internacional de Justicia consideró que esa consulta tenía que ver directamente con los desbordamientos de los poderes y atribuciones de dicho Tribunal: "No nos parece por ello que se solicite la opinión de la Corte respecto a aquellos fallos del Tribunal que podrían constituir una extralimitación de su competencia estatutaria"

Fue la Corte Internacional de Justicia que persistiendo excluyó cualquier posibilidad de dictaminar respecto a las acciones ultra vires. Tal y conforme hemos venido manifestando previamente debe de formularse una transparente diferenciación entre las prerrogativas y poderes de las organizaciones internacionales y los propios poderes, facultades o atribuciones de esas organizaciones, en tanto y en cuanto el problema que nos plantea el ultra vires es muchísimo más frecuente de lo que se piensa o teoriza en los órganos que componen la organización internacional que las que pueden incurrir de manera institucional. Según el profesor Huici (2003), el artículo 6 hace una diferencia entre actos ultra vires que violan las reglas de la organización relativas a la distribución de competencias entre los órganos (Unión Pro Paz sería un ejemplo) y actos ultra vires que violan las reglas de la organización relativas a la atribución de competencias a la organización internacional. Para este último caso cabría los efectos de los Fallos del tribunal Administrativo de las Naciones Unidas en los que se fijan indemnizaciones (ICJ. Reports, 1954, p. 5). En esta opinión consultiva, sin embargo, se establece la responsabilidad de la Organización por el incumplimiento del contrato de empleo, por lo que se reconoce que Naciones Unidas debía indemnizar al funcionario cuyo contrato fue rescindido sin su consentimiento.

Veamos, cuando la conducta, acciones o hechos ultra vires acontece en la propia organización que compromete seriamente a alguno de sus miembros, pues éstos no son terceros en lo que atañe a las propias reglas de la organización. Es muy relevante establecer y considerar que la misma organización internacional observe, explore y descubra su propia responsabilidad tal como lo prescribe el artículo 7 del Proyecto. No obstante ello, estimamos que debe de acentuarse que los artículos 2, 6 y 7 de esa normativa hacen alusión a la atribución, facultades de responsabilidad a la organización internacional, así como a los órganos, funcionarios y agentes, y no le otorga validez de los actos u hechos ultra vires. De esta manera la CDI (2001) estimo que "el acto, incluso si es considerado inválido, puede entrañar la responsabilidad de la OI. La necesidad de proteger a terceros exige que la atribución no se limite a los actos que se consideran válidos" pero eso si no desenmaraña la situación de la validez de los actos u hechos o los procedimientos y los mecanismos a fin de reconvenir la validez de un acto ultra vires.

A mayor abundamiento, dos casos a modo emblemático pueden instruir situaciones ultra vires: el tan famoso caso Tadic con el de Unión Pro Paz. En esta situación Tadic cuestionó firmemente los poderes del Consejo de Seguridad con el propósito de instituir un Tribunal especial que se encargara, asumiera procesalmente y condenara por todos los crímenes cometidos en la inmemorial Yugoslavia. Atendiendo la posición doctrinaria del abogado defensor de Tadic, se trataba indudablemente de un caso ultra vires, puesto que la competencia del Consejo de Seguridad tiene que ver directamente con las amenazas, contra la paz y contra la seguridad, pero no tiene que ver absolutamente nada 
con asuntos conexionados con crímenes de guerra o de lesa humanidad, razón suficiente por la cual la propia existencia de ese tribunal resultaba explicablemente controvertible.

Cuando hubo de poner de manifiesto su posición respecto de la excepción preliminar la Cámara de Apelaciones del Tribunal lo finiquitó expresando que la capacidad de poder describir o definir una amenaza contra la paz y la seguridad internacional establecido por la Carta es un ámbito muy amplio, solo limitado fundamentalmente por los principios fines y propósitos de la organización internacional; hay que tener en cuenta además que las medidas concedidas por la Carta no son taxativas, por lo que consecuentemente el Consejo de Seguridad no se habría conducido de manera ultra vires. En todo caso, es válida formular la pregunta si este tribunal tuvo o no competencia para interpretar el texto de la Carta en sentido de determinar y aplicar actos ultra vires.

A este respecto, repárese lo que explicita el profesor Klabbers (2002) cuando sostiene que la Cámara de Apelaciones utilizó los poderes que le confiere su propio estatuto y que son absolutamente ilimitados, y que para los efectos de definir o delimitar cualquier aspecto preliminar - como su propia competencia- sin embargo, no brinda argumentario legal alguno. En este caso el Tribunal concluye defendiendo su propia existencia. ¿En consecuencia, actuó entonces la Cámara ultra vires? Diáfanamente se visualiza que es un caso de competencia de la competencia; vale decir que se nos presenta la singular y paradójica situación de que las mismas organizaciones internacionales defiendan su propia existencia.

En virtud de la enorme capacidad de adaptación, y una suerte de afloración del instinto de supervivencia, o el de una justificación derivada y explicada de una inicial voluntad de los Estados, es muy poco probable que una organización internacional desapruebe su propia existencia y objete su exigencia de existir.

Con este bagaje de experiencias, el caso siguiente de actos ultra vires fue abundantemente discutida y de manera indirecta por la Corte en la Opinión Consultiva en relación a ciertos gastos incurridos. Recordemos que en la década de los 50, el Consejo de Seguridad sorprendentemente aprobó la intervención en la península de Corea, beneficiándose frente a la clamorosa ausencia de la Unión de República Socialista Soviética. En aquella circunstancia posiblemente la Asamblea General tuvo la sensación que esa oportunidad no iba a volver a repetirse, por lo que hubo de adoptar la Resolución Unión Pro Paz, a través de la cual se autoatribuía el poder y las facultades necesarias para enviar misiones de paz al Medio Oriente y al Congo. Esa resolución, qué duda cabe, fue legítima, porque tuvo el consenso de la amplia mayoría de los Estados que es prácticamente el poder constituyente de la organización - pero evidentemente no fue legal, porque presuntamente contravenía la Carta Constitutiva en cuanto a las competencias se refiere del Consejo de Seguridad. Por lo que la Opinión Consultiva respecto de ciertos gastos se vinculaba para conocer si los costos debían ser tomados en cuenta y asumidos por la organización internacional o por los Estados que participaron en esas celebradas misiones de paz. A renglón seguido la Corte aclaró que el Consejo de Seguridad tiene inicialmente la competencia primaria sobre aspectos de paz y de seguridad, pero no es exclusiva, por lo que se determinó que los gastos deberían ser asumidos plenamente por la Organización de Naciones Unidas. Nos parece que una opción puede verse en la práctica por medio de una supervisión y fiscalización interna que radica en que la organización internacional vigile discreta y eficientemente el cumplimiento de sus propios actos; estas acciones de supervisión y fiscalización la puede hacer la misma organización internacional o inclusive sus miembros. La supervisión se constituye en sí misma en un claro incentivo para cumplir celosamente las reglas de la organización. En la generalidad de los casos los órganos subsidiarios o secundarios se reportan y rinden cuentas ante uno o 
varios órganos principales; de esta manera la participación y el funcionamiento de los órganos secundarios o subsidiarios estarán gradualmente y eficazmente garantizados.

Con esta salvedad y marcando la ineluctable diferencia con los ordenamientos internos de los Estados miembros, en los que generalmente fluyen y existen procedimientos de cuestionamiento o impugnación de la validez de ciertos actos meramente administrativos o puramente legislativos, pues no existe un procedimiento análogo o semejante en la estructura de la Organización de Naciones Unidas, inclusive ninguna de las decisiones de los órganos de la propia Organización de Naciones Unidas o de sus agencias muy especializadas puede ser anulada o desconocida por una Corte. Porque ante la inexistencia de acuerdos no existe - por no estar debidamente constituido - un tribunal que sea lo suficientemente competente para pronunciarse o elevar su voz y presencia sobre la validez de ciertos actos de las organizaciones internacionales. En la práctica debe ser el Estado afectado - o inclusive los Estados afectados - los que rechacen aquellos actos que consideren inválidos o ineficaces. No obstante que tal cuestionamiento de carácter unilateral de los Estados devenga en una acalorada contradicción de los fines y propósitos de la organización internacional las que podrían conducirla finalmente a conflictos de poder y su ulterior fragmentación. La opción de salida continúa siendo acudir a la Corte Internacional de Justicia, vía consulta, pues nos lo proponen algunos estudiosos de la materia para todos los objetivos prácticos siempre que un dictamen consultivo que estime o declare la ilegalidad de una determinada decisión de la Organización de Naciones Unidas producirá el mismo efecto que una definitiva anulación.

Entre tanto, podemos sostener como conclusión que hasta la fecha no existen procedimientos o mecanismos diáfanos sobre el cómo actuar en los problemáticos casos ultra vires; si los actos serían declarados inválidos o anulados y quién o qué órgano será el llamado y tendría facultades para desarrollarlo. La sana doctrina internacional, sin embargo, nos propone que debe ser un órgano especial dotado con ensanchadas facultades jurisdiccionales. Además, habría que tomar en cuenta que no solo no existen pocos órganos jurisdiccionales con la suficiente capacidad para manifestarse al respecto, sino que incluso en los eventuales casos en que se producen puede ocurrir que esos pronunciamientos se tornan en obligatorio. Parte de la problemática que venimos comentando se identifica claramente en que estos casos problemáticos son muy escasos a nivel jurisprudencial. La doctrina internacional es disonante al respecto puesto que no están de acuerdo en muchos aspectos, razón por la cual se hace muy intrincado obtener apriorísticamente conclusiones que finalmente se traducen como simples conjeturas.

A modo de corolario la posición de la Corte Internacional de Justicia hasta la fecha ha sido imprecisa y ambigua en cuanto se refiere a las doctrinas que se engarzan con los poderes, prerrogativas o facultades de las organizaciones internacionales; el caso más frecuente que evidencia este desconcierto son las tan mentadas opiniones consultivas sobre reparación por daños; las consecuencias de esos fallos - poderes implícitos - y el de la legalidad sobre el uso de armas nucleares - poderes atribuidos -. En la primera situación se aborda a una organización internacional con competencias generales, el caso concreto es el de la Organización de Naciones Unidas, y en el segundo caso el de una organización internacional con competencias especializadas, verbigracia: Organización Mundial de la Salud. Sin embargo, la Corte Internacional de Justicia no se ha pronunciado ni puesto de manifiesto hasta este momento sobre el peliagudo asunto de la responsabilidad internacional por actos ultra vires.

Conviene no echar en saco roto toda la bibliografía apreciada y consultada, tanto de los estudios que versan sobre el derecho público como el de las relaciones internacionales, a estas alturas podríamos afirmar que no existe una teoría - como muchas otras - de las organizaciones 
internacionales; existen en diversos ámbitos debates en torno a puntuales aspectos como el de las funciones o atribuciones de los órganos de las organizaciones internacionales cuando de pronto las competencias son compartidas o superpuestas; la relación y vinculación con los Estados miembros y algunas cuestiones muy puntuales sobre la responsabilidad internacional. Esta ausencia hace posible que en gran medida la información sobre estas entidades se encuentre depositados en libros específicos muy especializados sobre Derecho Internacional Institucional, en los que se hace alude a la génesis, naturaleza, características y alcance de las organizaciones internacionales o a través de su actuación y conducción en casos concretos y en relación con otros sujetos, actores y agentes que tengan que ver con esta materia. Podemos sostener también que el hecho puntual de que exista una creciente preocupación por regular la conducta de las organizaciones internacionales, y que esta intranquilidad se manifieste en un proyecto de responsabilidad internacional o en importantes aportes de carácter doctrinal respecto de las acciones ultra vires, demuestra palmariamente que las organizaciones internacionales ejercen un notable impacto directo en la creación y desarrollo del derecho internacional público, y esto se genera en la medida en que cada vez más existen temas controversiales en las agendas nacionales que tienen una directa vinculación con la cooperación internacional y con el multilateralismo, todo ello se tornará más evidente en el futuro inmediato y en el estudio para la ejecución perentoria de la gobernanza global.

A este respecto el tan ansiado proyecto de responsabilidad de las organizaciones internacionales aun infortunadamente es solo eso, un proyecto nada más; pero es indudable refleja y proyecta, de cierta manera, la urgente necesidad de tener que contar con normas legales claras al respecto y definitivamente rechaza la idea de que las organizaciones internacionales no pueden incurrir en ilícitos. En tanto que los actos ultra vires pueden ser eventualmente subsanados, eso, en principio, no podría eximir a la organización internacional de responsabilidad alguna. No obstante, aún prevalecen y perduran grandes zonas grises en cuanto se refiere a la validez o a la nulidad de los actos o resoluciones adoptados ultra vires; en el sistema de la Organización de Naciones Unidas no existe lamentablemente procedimientos generales que se puedan utilizar ni seguir ante instancias jurisdiccionales con la suficiente competencia para manifestarse al respecto.

A continuación, se consignará: Los antecedentes de la Constitución de la Organización Mundial de la Salud (OMS), sus principios que la sostienen, las funciones que se le atribuye al funcionario principal administrativo y técnico de la organización especializada, cómo es el Director General.

\section{ANTECEDENTES DE LA CONSTITUCIÓN DE LA OMS}

La Constitución fue adoptada por la Conferencia Sanitaria Internacional, celebrada en Nueva York del 19 de junio al 22 de julio de 1946 y fue firmada el 22 de julio de 1946 por los representantes de 61 Estados, entrando en vigencia el 7 de abril de 1948. Las reformas adoptadas por la 26, la 29, la 39 y la 51 Asambleas Mundiales de la Salud (Resoluciones WHA26.37, WHA29.38, WHA39.6 y WHA51.23), que entraron en vigor el 3 de febrero de 1977, el 20 de enero de 1984, el 11 de julio de 1994 y el 15 de septiembre de 2005, respectivamente, se han incorporado al presente texto. El Perú es miembro de la OMS desde 1948.

\section{PRINCIPIOS DE LA CONSTITUCIÓN DE LA OMS}

La Constitución establece que, los siguientes principios son básicos para la felicidad, las relaciones armoniosas y la seguridad de todos los pueblos: 
1.-La salud es un estado de completo bienestar físico, mental y social, y no solamente la ausencia de afecciones o enfermedades.

2.-El goce del grado máximo de salud que se pueda lograr es uno de los derechos fundamentales de todo ser humano sin distinción de raza, religión, ideología política o condición económica o social.

3.-La salud de todos los pueblos es una condición fundamental para lograr la paz y la seguridad, y depende de la más amplia cooperación de las personas y de los Estados.

4.-Los resultados alcanzados por cada Estado en el fomento y protección de la salud son valiosos para todos.

5.-La desigualdad de los diversos países en lo relativo al fomento de la salud y el control de las enfermedades, sobre todo las transmisibles, constituye un peligro común.

6.-El desarrollo saludable del niño es de importancia fundamental; la capacidad de vivir en armonía en un mundo que cambia constantemente es indispensable para este desarrollo.

7.-La extensión a todos los pueblos de los beneficios de los conocimientos médicos, psicológicos y afines es esencial para alcanzar el más alto grado de salud.

8.-Una opinión pública bien informada y una cooperación activa por parte del público son de importancia capital para el mejoramiento de la salud del pueblo

9.-Los gobiernos tienen la responsabilidad de la salud de sus pueblos, que solo se puede cumplir mediante la provisión de medidas sanitarias y sociales adecuadas.

En base a estos principios se establece a la Organización Mundial de la Salud como organismo especializado de las Naciones Unidas.

\section{FUNCIONES DE LA OMS}

Actuar como autoridad directiva y coordinadora en asuntos de sanidad internacional; estimular y adelantar labores destinadas a suprimir enfermedades epidémicas, endémicas y otras; suministrar información, consejo y ayuda en el campo de la salud; contribuir a crear en todos los pueblos una opinión pública bien informada en asuntos de salud; y en general, tomar todas las medidas necesarias para alcanzar la finalidad que persigue la Organización, esto es, alcanzar para todos los pueblos el grado más alto posible de salud.

Advertimos, que la OMS tiene la autoridad para dirigir y coordinar los asuntos de salud a nivel internacional como epidemias y otras, debiendo proporcionar información oportuna a todos los Estados para que tomen todas las medidas necesarias para alcanzar la finalidad que persigue la Organización y que consiste en alcanzar para todos los Estados el grado más alto posible de salud.

La OMS a través de su Director no cumplió con informar de manera oportuna a la comunidad internacional, es decir a la totalidad de Estados, la pandemia que se avecinaba teniendo como origen el coronavirus covid19 a fin de que estos, puedan tomar las medidas preventivas con carácter urgentes y necesarias para alcanzar el grado más alto posible de la salud internacional. Es decir, la demora en proporcionar dicha información ha conllevado a que los Estados no hayan adoptado urgentemente las medidas necesarias para lograr el grado más óptimo en la salud y vida respectivamente de sus habitantes.

Si la OMS incumplió con sus funciones, que grado de responsabilidad se le puede atribuir según las normas del Derecho Internacional Público al Director General don Tedros Adhanom Ghebreyesus Seguidamente se definirá cuál es el concepto de responsabilidad internacional que estudia y regula las normas del Derecho Internacional. 


\section{ESTRUCTURA DE LA OMS. -}

La Asamblea Mundial de la Salud (Ilamada en adelante la Asamblea de la Salud) constituye un órgano de la OMS, además del Consejo Ejecutivo y la Secretaría.

Es la Asamblea de la Salud, a propuesta del Consejo quien nombra al Director General y le confiere instrucciones sobre cualquier asunto relacionado con la salubridad, constituyéndose en el funcionario principal técnico y administrativo de la Organización. El mandato del Director General es de cinco años y podrá renovarse una sola vez.

Ahora bien, es conveniente conocer como informó la prensa internacional (Reuters) la actuación de la OMS a través de su Director General respecto a la crisis mundial con sus impactos en la economía y las consecuencias sociales que se vienen agravando en nuestros días, provocada por el covid19.

Según la prensa internacional, específicamente Reuters, a finales de abril expresó: "La Organización Mundial de la Salud, en particular su director general, Tedros Adhanom Ghebreyesus, enfrentan críticas sobre la gestión de la pandemia venidas de Taiwán y sobre todo de la Casa Blanca, que acusa a la institución con sede en Ginebra de incompetencia y tener posiciones pro chinas.

El director general de la Organización Mundial de la Salud (OMS), el etíope Tedros Adhanom Ghebreyesus, pide a Donald Trump "no politice el virus", pero el presidente estadounidense estima que ha fallado "completamente" fallado por razones eminentemente políticas.

Trump acusó en días pasados a la OMS de "estar muy sesgada hacia China", tras recordar que en los inicios de la pandemia del coronavirus la entidad señaló que prohibir los viajes al gigante asiático, epicentro de este nuevo brote viral, no era aconsejable.

"La OMS realmente se equivocó", escribió. "Por alguna razón, está financiada en gran parte por Estados Unidos, pero muy centrada en China. Vamos a analizarlo más de cerca", agregó, dejando en suspenso un recorte de su aporte.

Estados Unidos estima que la OMS tardó demasiado en tomar conciencia de la magnitud de la epidemia y, sobre todo, el haber disimulado la gravedad del nuevo coronavirus.

La tardanza de diez días de tergiversaciones para decretar la necesaria emergencia sanitaria internacional por parte de Tedros, la opacidad de las autoridades chinas que necesitaron hasta 11 días para hacer pública la secuenciación del ADN de la COVID-19, el haber indicado en un primer momento que había pocos indicios de una transmisión de la enfermedad entre humanos y, sobre todo, la constante celebración del director de la OMS hasta la "transparencia" de Pekín en la crisis acabaron por ser juzgada excesivamente políticas en Washington.

"Esta deferencia fue realmente excesiva", dice en Le Monde Suerie Moon, codirectora del Centro para la Salud Global del Instituto de Estudios de Posgrado sobre Desarrollo e Internacional, "pero no es suficiente para acusar a la organización de tener un sesgo chino". "Era importante asegurarse de que el canal con China permaneciera abierto, porque las primeras semanas eran cruciales para reunir información para aprender más sobre el virus", agrega. 
Mientras tanto, Taiwán se suma a las críticas a Tedros, estimando que el jefe de la OMS debe disculparse ante Taipéi por haber acusado al gobierno de la isla de alentar a los taiwaneses a atacar la OMS por su gestión de la pandemia.

Tedros afirmó que era objeto de una campaña "racista" en su contra con la venia del Ministerio de Relaciones Exteriores de Taiwán, país excluido de la OMS a pedido de China, que reivindica la soberanía sobre la isla rebelde.

Entretanto, en las redes sociales circula una imagen del doctor Tedros con los ojos tapados por una bandera china y llevado por una correa por el presidente chino Xi Jinping. Una petición en línea con más de 800.000 firmas pide la renuncia del jefe de la OMS.

Mientras, en Ginebra, donde la organización fundada en 1948 tiene su sede, relativizan las acusaciones. "Estamos movilizados 24 horas al día, 7 días a la semana. Estas son las críticas habituales. En tiempos de crisis, siempre debe haber una salida y un culpable", matiza la Dra. Sylvie Briand, jefa del departamento de enfermedades infecciosas".

\section{CONCLUSIONES:}

UNO. - Entre las organizaciones internacionales, la credibilidad y confianza de la Organización Mundial de la Salud (OMS) ha sufrido un enorme deterioro. Su Director General, el eritreo Tedros Adhanom, ha sido duramente cuestionado principalmente por Estados Unidos, acusándolo de proteger a China por su incumplimiento de informar a tiempo de la pandemia y de ocultar información sobre este fatal virus.

DOS, - La OMS no dijo nada sobre la letalidad del virus y su alcance internacional de mortandad en noviembre de 2019, cuando el virus ya se había desencadenado en China y se encontraba además fuera de control.

TRES. - El director General de la OMS se negó a declarar la pandemia hasta el 10 de marzo, pese a que ya se había extendido muy significativamente a países europeos; y el Covid-19 ya se había asentado con fuerza en Europa.

CUATRO. - La OMS tampoco ha dicho la verdad respecto al virus de procedencia china. Cada vez es más la población que toma conocimiento de que el origen del virus no brotó de un mercado de animales en Wuhan. Es mucha la coincidencia que este virus pandémico haya surgido a escasos metros de un laboratorio de experimentación biológica y molecular de máxima seguridad cuyo accionista principal es George Soros.

CINCO. - La OMS ha sido negligente y falsaria: en diciembre, cuando la bomba pandémica ya bullía, pues debió de haber recomendado cerrar las fronteras de los Estados con China, así como hacer acopios masivos de material sanitario fundamental para combatir al virus instando a todos los Estado a fabricar ese material de modo inmediato.

SEIS. - Que la Organización Mundial de la Salud no haya sido capaz de poner su nombre científico de Covid-19 en fecha oportuna.

SIETE. - Otro de los benefactores de la OMS es el magnate Bill Gates quien presagió una gran pandemia no porque sea un inteligente nigromante, sino porque fabrica vacunas, 
transgénicos y agroquímicos. Su fundación aporta millones de dólares a la Organización Mundial de la Salud, con lo cual posee capacidad de decisión sobre qué medicamentos se certifican y cuáles se impugnan o retrasan.

\section{REFERENCIAS BIBLIOGRÁFICAS:}

- Amerasinghe, C. F. (2005). Principles of thel Institutional Law of International Organizations ( $2^{\mathrm{a}}$ ed.). Cambridge University Press.

- Comisión de Derecho Internacional. Proyecto sobre Responsabilidad de las Organizaciones Internacionales.

- Dunoff \& Thachtman (Eds.) (2009). Ruling the world? Constitutionalism, Institutional law and Global Governance. New York: Cambridge University Press.

- Huici, L. (2007). El hecho internacionalmente ilícito de las Organizaciones Internacionales. Barcelona: JM Bosch.

- Junne, G. (2001). International Organizations in a period of globalization: new (problems of) legitimacy. En M. Coicaud \& V. Heiskanen (Eds.), The legitimacy of International Organizations. New York: United Nations University Press.

- Keohane, R. \& Nye, J. (2002). Complex Interdependence and the Role of Force (1977). En R. \& Art, International Politics: Enduring Concepts and Contemporary issues . Pearson.

- Klabbers, J. (2002). An introduction to International Institutional Law. New York: Cambridge University Press.

- Krasner, S. (1983). International Regimes. London: Cornell University Press.

- Krasner, S. (2001). La soberanía perdurable. Revista Colombia Internacional.

- Krasner, S. (2001). Soberanía, hipocresía organizada. Paidós.

- Ridruejo, J. (2010). Curso de Derecho Internacional Público y Organizaciones Internacionales (13aed.). Madrid: Tecnos.

- Rodríguez, A. (1994). Lecciones de Derecho Internacional Público. Madrid: Tecnos.

- Urueña René (2008), Derecho de las Organizaciones Internacionales, Bogotá. Universidad Los Andes.

Fecha de recepción: 22 de mayo de 2020

Fecha de aceptación: 01 de junio de 2020 